\title{
Is neighborhood level Jobs-Housing Balance associated with travel behavior of commuters?: a case study on Dhaka City, Bangladesh
}

\author{
Md Hamidur Rahman ${ }^{1 凶}$ - Fajle Rabbi Ashik ${ }^{2}$ \\ ${ }^{1}$ Asian Disaster Preparedness Center (ADPC), Dhaka-1206, Bangladesh. \\ ${ }^{2}$ BUET-Japan Institute of Disaster Prevention and Urban Safety, Dhaka, Bangladesh. \\ 凶sumon.adpc@gmail.com
}

\begin{abstract}
Being one of the densely populated cities of the world, city dwellers of Dhaka have to face severe traffic congestion daily while commuting for different purposes. According to the World Bank report, Dhaka is losing around 3.2 billion working hours daily as the current average driving speed is about seven kilometers per hour. To ease traffic congestion, urban policymakers around the world are concentrating on the geographical balance between the locations of jobs and housing. Despite the apparent acceptance of jobs-housing balance as a policy tool to guide urban development, little empirical research has been carried out on jobs-housing balance and its relation to the travel behavior of the residents. This study aims to close this research gap by: (a) quantifying neighborhoodlevel jobs-housing balance; (b) investigating whether there are any significant differences in commuting time and distance of the resident workers in correspondence with different Job-Housing Ratio (JHR) values of neighbourhoods. This paper uses Traffic Analysis Zones (TAZs) demarcated on the Revised Strategic Transport Plan as a unit of measuring the Job-Housing Ratio, and then, TAZs have been categorized into three groups, named as Housing-rich, Balanced, and Employment-rich, in terms of the recommended range of Job-Housing Ratio. Residents' home-based commuting data have been calculated from 16,000 households who participated in Household Interview Survey of Revised Strategic Transport Plan 2015. Results demonstrate that Housing-rich neighbourhoods have a significantly longer commuting distance and time than both Balanced and Employment-rich neighbourhoods. Above all, both commuting time and distance show exponentially declining relation, but with a decreasing rate, in correspondence with JHR. The study output suggests that the achievement of a balance between jobs and housing in a neighborhood would be beneficial for the people to economize the commuting time and distance.
\end{abstract}

\section{Highlights for public administration, management and planning:}

- There is a significant difference in people's average commuting time and distance based on the balance of their living places jobs-housing distribution.

- On average, Housing-rich neighborhoods of Dhaka city tend to have average 8.17 minutes $(2.92 \mathrm{~km})$ longer commuting time (distance) than Employment rich neighborhoods.

- Housing options with affordable commuting distance to jobs location would create economically and environmentally balanced communities.

- Future growth of cities and urban travel patterns of the residents is required to maintain an appropriate job-housing balance.

\section{Keywords}

Jobs-Housing Ratio, Commuting time, Commuting distance, Traffic Analysis Zones, Dhaka City

Received: 16 August 2020

Received in revised form: 28 November 2020

Accepted:

04 December 2020 


\section{Sciendo}

\section{Introduction}

Jobs-housing imbalance occurs when a number of jobs available in an area differ significantly from the number of housing available in an area. A community is considered a balanced one when the number of jobs and housing are approximately equal (Sultana 2002). If employed residents do not have enough jobs available where they reside, they have to travel a longer distance. Jobs-housing balance is one of the policy tools used for land use development in developed countries (Wu et al. 2015; SACOG 2012; Miller 2010). Many city development authorities and transport authorities of developed countries have adopted Job-housing balance as a tool to reduce travel demand and to increase the quality of place (Wu et al. 2015). The spatial location where people reside and work, shapes the travel patterns (Cervero 1989; Ewing et al. 1996; Zhao et al. 2009; Loo and Chow 2011; Bento et al. 2005; Downs 2004; Horner 2008; Wang and Chai 2009). Previous studies have revealed that Built Environment (BE) has a tremendous impact on travel behavior, i.e., on Vehicle Hours Travelled (VHT) (Frank \& Pivo 1994; Cervero and Duncan 2006; Weitz et al. 2003). A reduction of Vehicle Hours Travelled (VHT), and Vehicle Miles Travelled (VMT) would improve the social, economic, and environmental conditions of a city.

The capital city, Dhaka, is one of the fast-growing megacities around the world, with some 21 million people (Dhaka Population 2020). Due to the current urban development policy, the city is experiencing suburbanization through expanding medium to low-density residential areas in the peripheral regions of the city. Progressing motorization is adding more stress to road users as it would result in increased commuting time, traffic congestion, and environmental pollution in the city. Moreover, the living conditions of low-income groups are worsening who reside in the central areas of the city. On behalf of the Bangladesh Government, Rajdhani Unnayan Kartripakkha (RAJUK) which is a public agency responsible for coordinating urban development in capital city is implementing Dhaka Structure Plan (DSP) spanning for 20 years period (Dhaka Structure Plan 2016-2015). Dhaka Transport Coordination Authority (DTCA) is updating the "Strategic Transport Plan for Dhaka" (STP) in 2005, a 20-Year Urban Transportation Policy (2004-2024) as a "Revised Strategic Transport Plan (RSTP)" project (DTCA 2015). Both land use and transport plan for the city is working for improving the effective management of employ- ment opportunities and housing need through policy like Transit-Oriented Development (TOD). Literature suggests that Job-housing balance is one of the precursors to the effective implementation of the TOD policy. But there is a question to what extent the Job-Housing Ratio (JHR) would work as an intervention instrument.

DSP 2016-2035 plan has divided the entire jurisdiction area into six zones and fixed it to have a target to achieve balanced growth in housing and jobs locally. The Dhaka Metropolitan Region (DMR) would accommodate nearly 12.87 million Jobs in 2035 at the rate of an average of 2.0 persons per household, which gives the population-employment ratio of about $50 \%$ in the RDP area (Dhaka Structure Plan 2016-2035). This plan indicated a metropolitan scale or regional scale ratio, which can depict an overall scenario for the region. But when planning authority would go for Detailed Area Plan, JHR is needed to be quantified for a more disaggregated level, i.e., neighborhood level.

Due to lack of adequate database in census and secondary sources, there are no empirical studies found for Dhaka city which test the hypothesis of the addressed relationship between Jobs-Housing Ratio and travel behavior raised by international literature. Moreover, there is a significant research gap in studying the built environment and travel behavior in developing country perspective. Transferability of developing country evidence to the developing context leads to a valid question given socioeconomic, mobility pattern, and spatial structure differences. Hence, the current study would quantify the JHR at the neighborhoods of Dhaka city as a representative of developing country of South Asia and would try to find its association with residents commuting time and distance for work trips. Local planning authorities would find this output helpful to relocate employment opportunities from central areas to planned urban agglomeration areas. Planners would be able to see the existing jobs-housing scenario in different parts of the city. It would delineate the parts of the city where there are more jobs than people residing in that geographical unit. Also, areas that are more occupied with housing units with lower employment options. 


\section{Literature Review}

The concept of Job-housing balance is derived from initiatives of the self-contained community by Howard, Purdom, and Munford (Giuliano 1991). Giuliano (1991) defines Job-housing balance is "the distribution of employment relative to the distribution of Workers in a given geographic area". The proportions of locally residing workers in a defined area determine the degree of balance. Margolis (1957) first practiced the concept of Job-housing balance for a balanced community where the ratio of employment to residents ranging from .75 to 1.25 (Margolis 1957).

Job-housing balance would have a direct impact on the commuting distance or time (Levinson and Kumar 1994; Peng 1997; Cervero and Duncan 2006; Frank 1994; Horner \& Mefford 2007; Niedzielski et al. 2015; Zhao et al. 2011; Ta et al. 2016; Aslam et al. 2019). Zhao et al. (2009) and Peng (1997) suggest that marginal reduction in commuting time or distance is small when JHR is beyond 1 and found a non-linear relationship between commuting distance and JHR. Zhao et al. (2011) maintain that after controlling transport accessibility, population density, and worker's socioeconomic characteristics, JHR has a significant influence to reduce commuting distance. Ta et al. (2017) study the past and present trends of commuting patterns in different cities of China, and suggest that the government should intervene for the achievement of Job-housing balance to reduce the commuting distance. Besides, people would choose more sustainable modes, as people have to make short trips to the workplace (Cervero \& Duncan 2006), and, hence, an effective Job-housing balance would improve the active and NMT use for local travel. Furthermore, Cervero (1996) suggests that Job-housing balance has the potential to reduce trip generation and attraction.

Researchers have quantified the JHR mainly through jobs/housing units (Ewing et al. 1996; Cervero 1991) or jobs/employed-residents ratio (Cervero 1989) or by jobs/resident workers ratio (Giuliano 1991). Besides, jobs to housing units can also be used as ratio as it would reveal the real supply of housing market (Weitz et al. 2003). Different study has conducted the impact of Job-housing balance on different geographical scale-like, countylevel (Giuliano 1991; Cervero 1996, Miller 2010); census tract level (Frank 1994; Yang \& Ferreira 2005; Zhao et al. 2009). Table 1 shows different peer-reviewed studies that used Job-housing balance by ratio. Researchers like Peng (1997) proposed to use the "meso-level" of geographic unit defined by the mean or median actual commute distance of the region to measure Job-housing balance.

\section{Study Area Profile}

The selection of geographical units for the Jobhousing balance study depends on the urban structure, planning goals, and role of areas in related transport and land use plans. Many of the previous studies delineated commuter shed by average commuting distance by the workers as a geographical unit to access Job-housing balance. As mentioned, this study would try to depict the neighborhood Jobhousing balance, and its impact on travel behavior, hence, Traffic Analysis Zones (TAZs) used in RSTP2015 is taken as a unit of study. Moreover, the idea of commuter shed creation through average travel distance or commuting time would be more appropriate if the study were conducted on the Metropolitan level-map showing distributions of TAZ's.

Table 1 Recommended Jobs-housing balance ratios

\begin{tabular}{lll}
\hline Study & Measurement & Recommended Ratio \\
\hline Cervero (1989) & Jobs to household ratio & Ceiling ratio 1.5 (multiple workers) at a city level \\
Ewing et al. (1996) & Jobs to household ratio & $1.3: 1-1.7: 1$ for 3-5 miles area around a development site \\
Frank and Pivo (1994) & Jobs to household ratio & $0.8: 1-1.2: 1$ for census tracts \\
Peng (1997) & Jobs to household ratio & $1.2: 1-2.8: 1$ for TAZs covered by a 5-mile radius of a central TAZ \\
SCAG (2001) & Jobs to household ratio & $1: 1-1: 1.29$ Commute shed within 14 miles radius of job centers \\
Giuliano (1991) & Jobs to population ratio & NA for County level \\
Cervero (1991) & Jobs to housing units ratio & $1.4: 1-1.6$ for Medium-sized community \\
Cervero (1996) & Jobs to employed residents ratio & $0.8: 1-1.25: 1$ at the city level \\
Yang and Ferreira (2005) & Jobs to employed residents ratio & NA for floating areas with census tracts "Whose centroids \\
& & are within 10 miles radius of the target census tract" \\
\hline
\end{tabular}

Source: Adapted from Wu et al. (2015) 
Dhaka North and South City Corpotation Wards (TAZs)

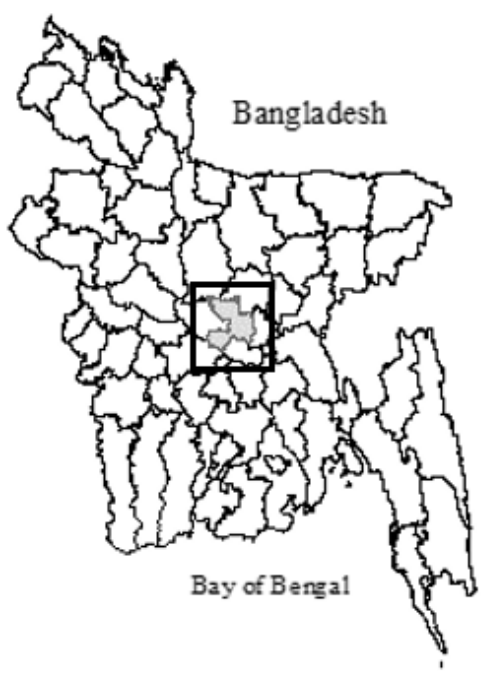

Dhaka District
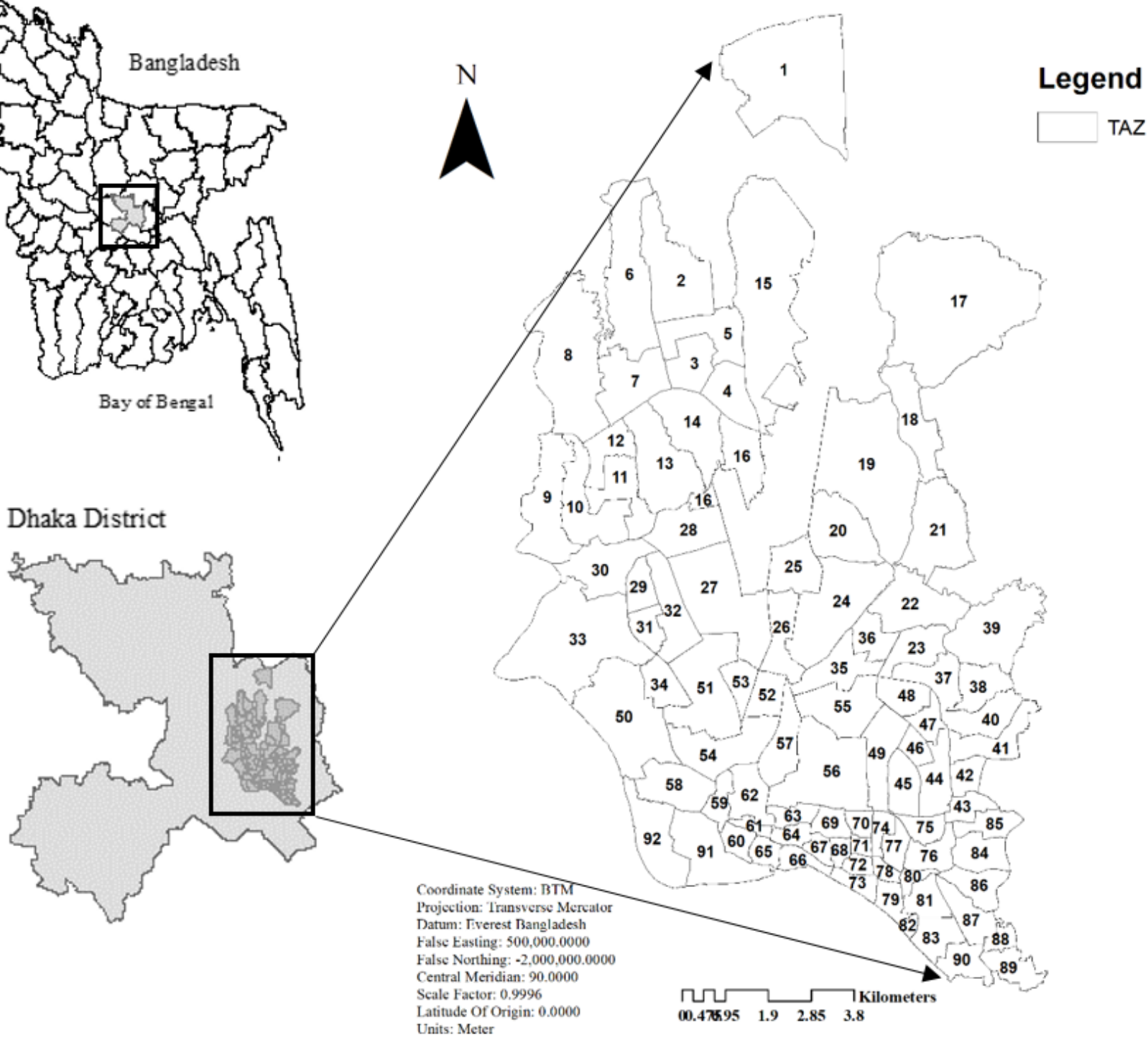

Fig. 1 Traffic Analysis Zone (TAZ) map of Dhaka North and South City Corporation

Table 2 Sources and functions of the dataset used in the research

\begin{tabular}{lll}
\hline Dataset & Functions & Data Source \\
\hline Number of Jobs & To derive the Job-housing Ratio & Economic Census Report-22013 \\
Number of Households & To derive the Jobs-housing ratio & District Report: Dhaka) \\
Road Network & To use for network analysis & BBS $^{a}, 2011$ \\
Traffic Analysis Zones (TAZ) & To delineate the neighborhood boundary & RSM $^{b} 2018$ \\
Household Interview Survey & To derive travel mode choice, commuting time & RSTP-2015 (DTCA) \\
\hline
\end{tabular}

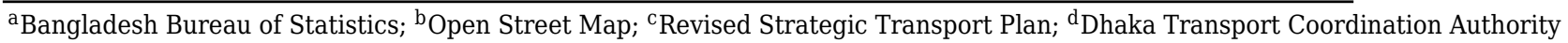




\section{Methodology}

\subsection{Data}

The study used Economic Census Report 2013 of Bangladesh Bureau of Statistics for identifying the total numbers of jobs and households at the TAZ level. Besides, Household Interview Survey (HIS) of RSTP-2015 has been used to derive the average commuting time and distance of the residents of different TAZ. The survey was conducted on 16,000 households across the city. The total number of people employed in a particular mouza which the lowest administrative unit for survey or cadastral purpose, has been considered as the number of jobs to that mouza. Later, mouza level data has been aggregated to the ward level or TAZ level. Data has been projected for the year 2018, as travel data is also projected for that period.

\subsection{Job-Housing Ratio derivation}

Job-housing balance has been calculated as a ratio of the number of jobs and the number of households in this study. The equation to calculate the ratio is as follows:

$$
J H R=\frac{J_{i}}{H_{i}}
$$

Where, $\mathrm{J}_{\mathrm{i}}=$ number of jobs (employed population) of neighborhood $\mathrm{i}, \mathrm{H}_{\mathrm{i}}=$ number of Households in the neighborhood i. As mentioned earlier, census data related to the number of jobs and households have been projected for the year 2018 by the following equation:

$$
P_{n}=P(1+r)^{n}
$$

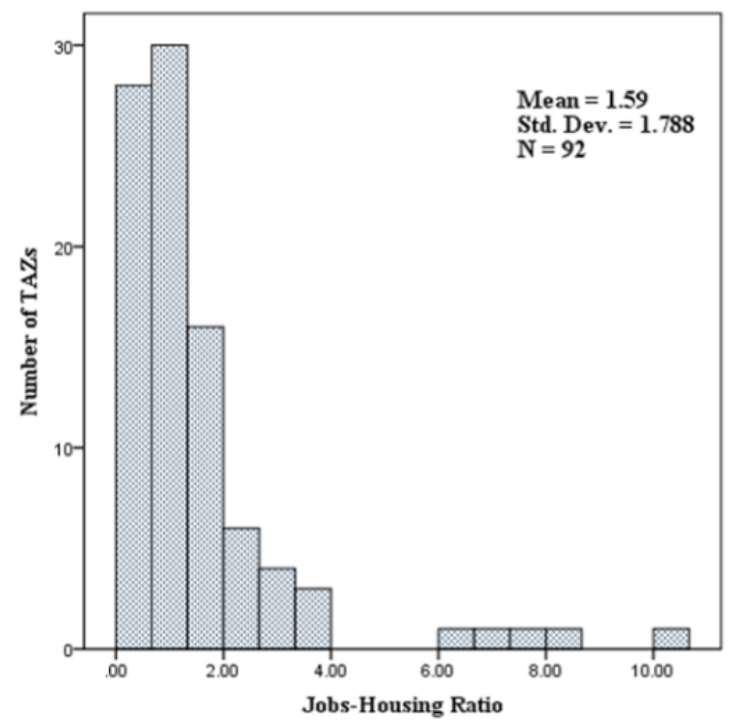

(a)
Where $P_{n}=$ household or employment at the end of $n$ years (projected year); $\mathrm{P}=$ number of jobs or households for the base year; $n=$ Number of years; $r=$ employment or household growth rate.

However, there are several challenges to quantify the ratio and defining the appropriate ratio for land use development control and TOD implementation. Moreover, for Dhaka city, informal job-share a significant portion of total employment in the city. Accurate information regarding formal and informal job opportunities in an area is hard to aggregate at the neighborhood level. Hence, the actual number of jobs available in the study units might be higher than the estimated employed population used in this study.

\subsection{Average Commuting time Time for Work Trips}

The study used the work travel trip to calculate the average commuting time of the resident by different travel modes by the following formula:

$$
\text { Average comm. time }=\frac{\text { Sum of comm. time }}{\text { Total work trips }}
$$

\subsection{Average Commuting Distance for Work Trips}

As part of the Household Interview Survey of RSTP, respondents were asked to tell their workplace TAZ, and the distance they have to cover for reaching their work destination. Based on this information, this study derived the average work trip travel distance for the entire TAZ.

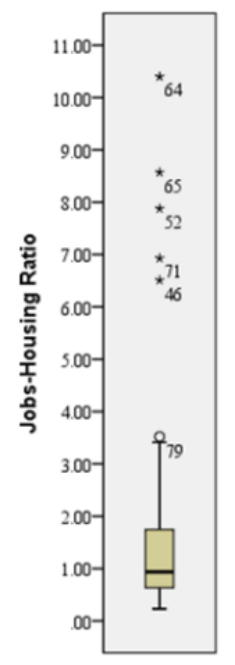

(b)

Fig. 2 (A) Histogram showing JHR for the studied TAZs; (B) Box plot showing outlier of JHR values. 


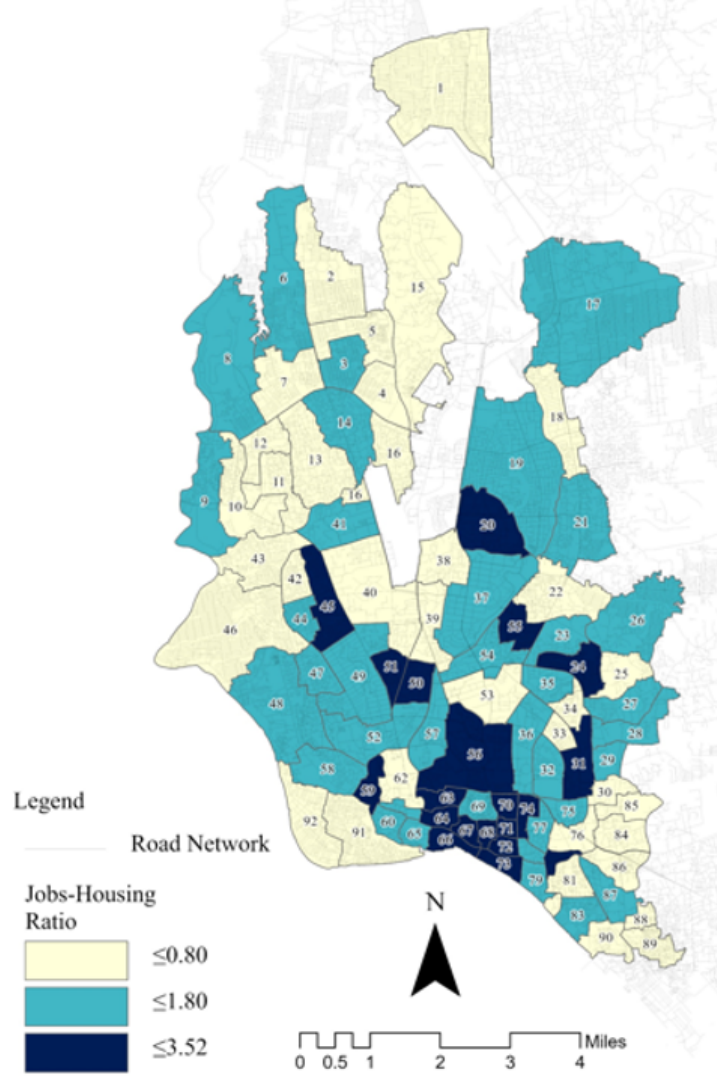

(a)

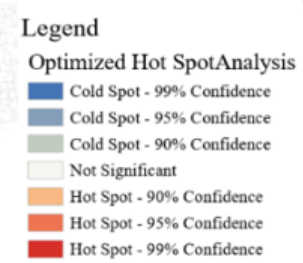

(b)

Fig. 3 (A) Variation of Job-housing Ratio value of TAZs of Dhaka; (B) Optimized Hot Spot analysis map of Job-housing Ratio values of TAZs of Dhaka

\section{Results}

The Job-housing balance has been calculated at the TAZ level, which is delineated by the two city corporations ward boundary (see Figure 1). The total employed population in a particular TAZ has been counted as the number of jobs. Due to variation in TAZs' size, land use pattern, the total number of jobs and households varied across the city.

Here, the overall JHR of the city is 1.59 , which is balanced in terms of recommended ratio in different other studies (Peng 1997; Cervero 1996). However, the positive skewness of ratio value indicates that the distribution of JHR values deviates from a normal distribution. This issue can be observed from the histogram also (see Figure 2A), where a majority of the ratio value is below the mean or median of the data set. From the box plot, TAZ, with the extreme value of the JHR can be observed (see Figure 2B). A city would have a specialized area for its commercial, industrial, or institutional zones. The predominant nature of land use in different parts of the city would impact the degree of jobs-housing balance. Hence, few TAZ would act like a commercial or institutional hub where the JHR value would be higher. However, an adequate supply of jobs and housing in areas would help to change the travel pattern of the residents if neighborhoods become self-contained with adequate infrastructural facilities for different income groups.

\subsection{Neighborhood classification in terms of the Job-Housing ratio}

Neighborhoods have been categorized into three different groups based on the recommended range of JHR at the TAZ level. In this study, neighborhoods with JHR values between 0.80 to 1.80 are identified as balanced neighborhoods as there is an opportunity both for housing and jobs. Neighborhoods with a ratio value less than .80 are identified as Housing-rich areas where there is an insufficient 
Table 3 Estimation of jobs-housing ratios for the overall sample (N=92)

\begin{tabular}{lrrrrrr}
\hline Variables & Mean & Median & STD & Min & \multicolumn{1}{l}{ Max } & Skewness \\
\hline No. of Jobs & 24583 & 19225 & 17331 & 2852 & 110381 & 1.841 \\
No. of Households & 23726 & 18211 & 18305 & 1676 & 96777 & 1.571 \\
Jobs-Housing Ratio & 1.59 & 0.935 & 1.78 & 0.23 & 10.40 & 3.019 \\
\hline
\end{tabular}

supply of jobs for local residents. Whereas, neighborhoods with a JHR greater than 1.80 are considered Employment-rich areas as jobs are abundant.

Table 4 Clustering of Neighborhoods based on Job-housing Ratio values

\begin{tabular}{llll}
\hline Groups & $\begin{array}{c}\text { Jobs-Housing } \\
\text { Ratio }\end{array}$ & $\begin{array}{c}\text { Number of } \\
\text { neighborhoods }\end{array}$ & $\begin{array}{c}\text { *Category } \\
\text { Type }\end{array}$ \\
\hline Group 1 & $<=.80$ & 36 & Housing Rich \\
Group 2 & $.81-1.80$ & 36 & Balanced Ratio \\
Group 3 & $1.81+$ & 20 & Employment Rich \\
& Total & 92 & \\
\hline
\end{tabular}

* Here, the naming of category types has been adopted from Sultana, 2002

As the literature suggests that balance in neighborhood job-housing facilities would reduce vehicle travel distance or commuting time of the residents. A balance in the job-housing provision at neighborhood-level would affect both employment efficiency and labor force efficiency. Here, employment efficiency is that the share of workers who reside locally, whereas labor efficiency is the share of residents who work locally. Both of these would affect travel patterns, which involves mode choice, commuting time, and travel distance. Hence, the next section would explore the relationship between residents' average work trip commuting time and the corresponding JHR of the neighborhoods they reside in.

Figure 3A shows the degree of Job-housing balance varies across the city. It's hard to visually identify whether the distribution of the values of the ratio is random or clustered. Hence, Optimized Hot Spot Analysis has been performed in the ArcGIS Pro environment using the Getis-Ord Gi* statistic to identify statistically significant spatial clusters of high values (hot spots) and low values (cold spots). Figure 3B shows that TAZs in the southern part of the have statistically significant clustering of high JHR values. The majority of the TAZs in the hot sport zones are neighborhoods of Old Dhaka (i.e., Shakhari Bazar, Bangshal, Begum Bazar, etc.) where both household and employment floorspace density is higher with mixed-use development (Rahman et al. 2019) Though the JHR data were skewed, output analysis is reliable as Getis-Ord Gi* statistic is asymptotically normal (Optimized hot spot analysis ArcGIS pro Documentation 2019).

\subsection{Impact of Job-housing balance on average work trip commuting time and travel dis- tance}

It is necessary to observe how the travel behavior of the residents get affected by the balance of jobs and housing. In this study, average work trip commuting time has been calculated for all the TAZs or neighborhoods (see Figure 4). This map represents the neighborhoods where people have to spend more time on work purposes. Neighborhoods covering Dhanmondi, Mohammadpur, Adabor, Technical, Shyamoli Shewrapara, Monipur, Pallabi, Matikata, Kafoul Mirpur-1, 2, etc. have greater commuting time than other parts of the city. These neighborhoods are located in "housing rich" zones, as evident from the JHR map (see Figure $3 \mathrm{~A})$. Hence, it is assumed that residents of these areas have to travel outside their residing place due to the low local job supply. Hence, residents need to use different modes, i.e., private cars, public buses, CNG for traveling in different parts of the city. As a result, the existing road network becomes saturated in peak hours; severe traffic jam is observable in these areas. Another significant finding is that the southern part of the city where there is a significant cluster of high JHR values (see Figure 3B) have a lower average work trip commuting time (see Figure 4).

Table 5 Variation of commuting time and distance in three neighborhood typologies

\begin{tabular}{lll}
\hline \multirow{2}{*}{ Neighborhood types } & $\begin{array}{l}\text { Commuting } \\
\text { time (minutes) }\end{array}$ & $\begin{array}{l}\text { Commuting } \\
\text { distance }(\mathrm{Km})\end{array}$ \\
\hline Housing-rich & 36.98 & 8.03 \\
Balanced & 33.71 & 7.24 \\
Employment-rich & 28.81 & 5.10 \\
& $\mathrm{~F}=8.554$ & $\mathrm{~F}=4.348$ \\
& $(0.000)$ & $(0.91)$ \\
\hline
\end{tabular}

A one-way analysis of variance has been conducted to evaluate whether there is any significant difference in the average commuting time and dis- 


\section{sciendo}

tance between different neighborhood types identified based on their JHR values. And Post Hoc analysis has been carried out to evaluate pairwise differences in average commuting time and distance between neighborhood types. Table 5 confirms that, overall, there is a significant difference in the neighborhood's average commuting time and distance. The trips generated from housing rich neighborhoods have on average longer commuting time and distance than Balanced or Employmentrich neighborhoods, and Post Hoc analysis asserts that this finding is also statistically significant for all cases except for one case, the travel distance between Housing-rich and Balanced neighborhoods (Table 6). On average, Housing-rich neighborhoods of Dhaka city tend to have an average of $8.17 \mathrm{~min}$ utes $(2.92 \mathrm{~km})$ longer commuting time (distance) than Employment rich neighborhoods.
Table 6 Comparison of the average commuting time and distance using Post Hoc between neighborhood types

\begin{tabular}{lll}
\hline Neighborhood Types & $\begin{array}{l}\text { Commuting } \\
\text { time } \\
\text { (minutes) }\end{array}$ & $\begin{array}{l}\text { Commuting } \\
\text { distance } \\
(\mathrm{km})\end{array}$ \\
\hline $\begin{array}{l}\text { Housing Rich vs. Balanced } \\
\text { Housing Rich }\end{array}$ & $3.28(0.061)$ & $0.79(0.633)$ \\
$\begin{array}{l}\text { vs. Employment rich } \\
\text { Balanced vs. Employment rich }\end{array}$ & $4.89(0.02)$ & $2.13(0.091)$ \\
\hline
\end{tabular}

To understand the association between JHR and commuting time, and JHR and commuting distance, curve estimation models have been carried out: exponential models are found to be the best model to explain both commuting time and distance in correspondence to JHR, as this model has the highest statistically significant $R^{2}$ value with a low standard error of the estimates. From Figure 5 and 6 , both commuting time and distance of homebased generated work trips declines exponentially

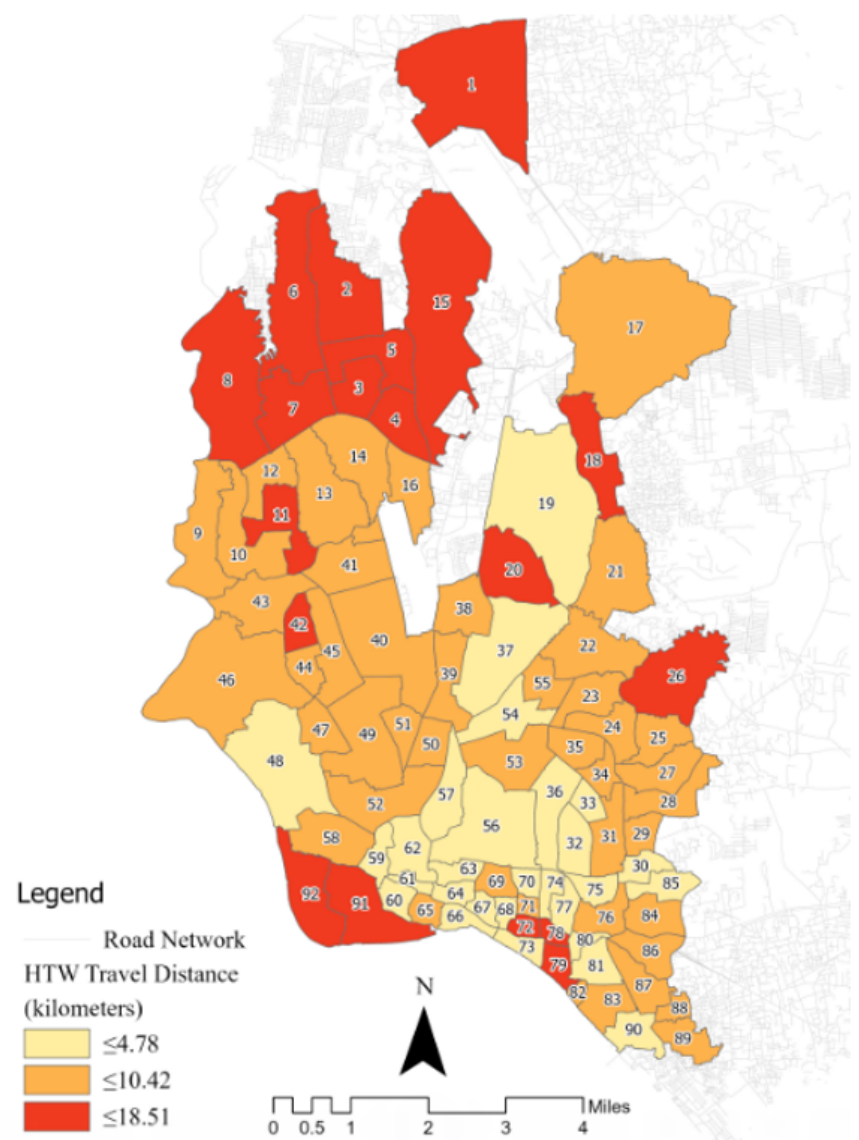

Fig. 4 (A - left) The variation of the average home to work commuting time; (B - right) average home to work travel distance of TAZs of Dhaka. 


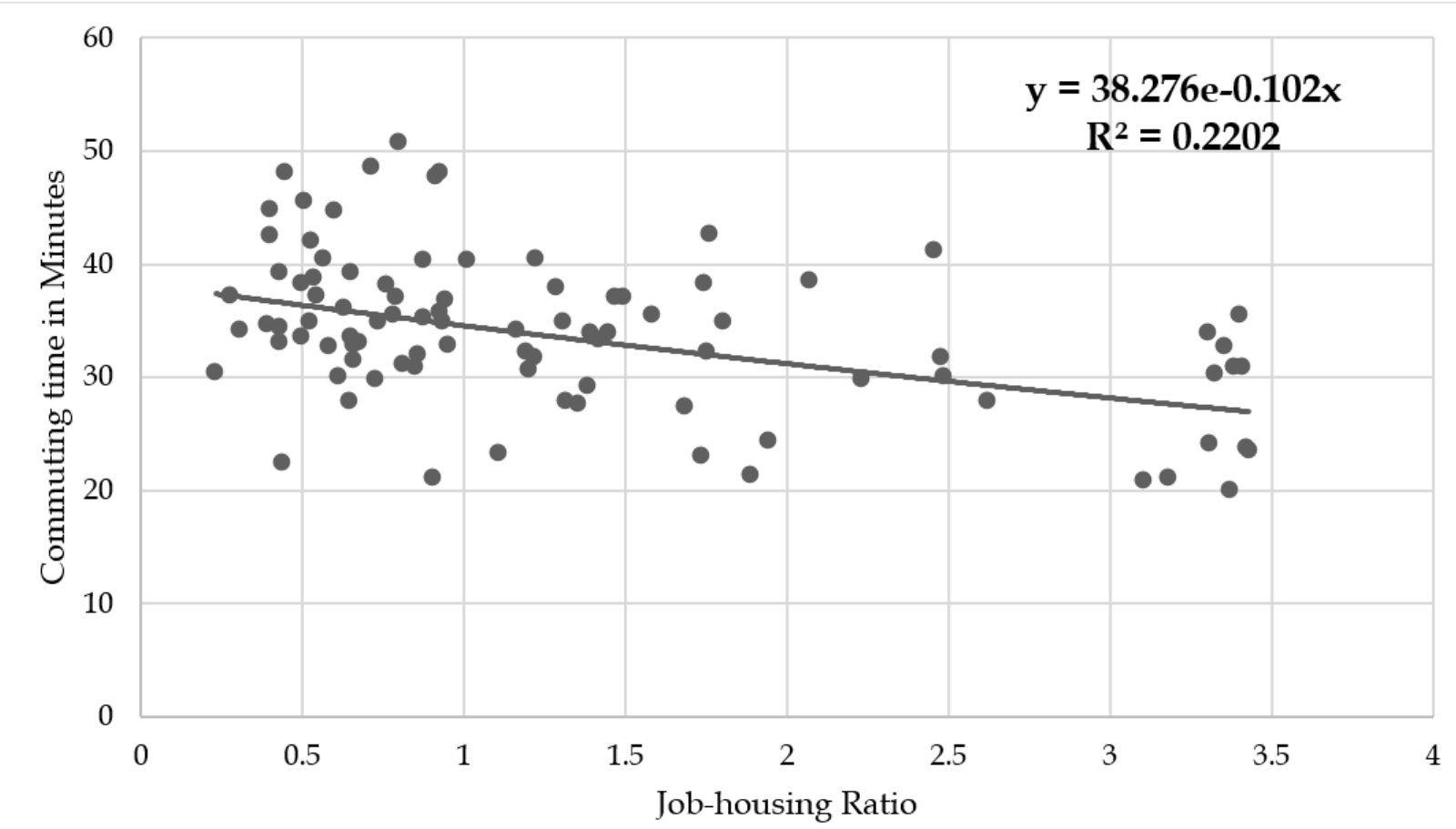

Fig. 5 Average commuting time of TAZ and their corresponding Job-housing Ratio.

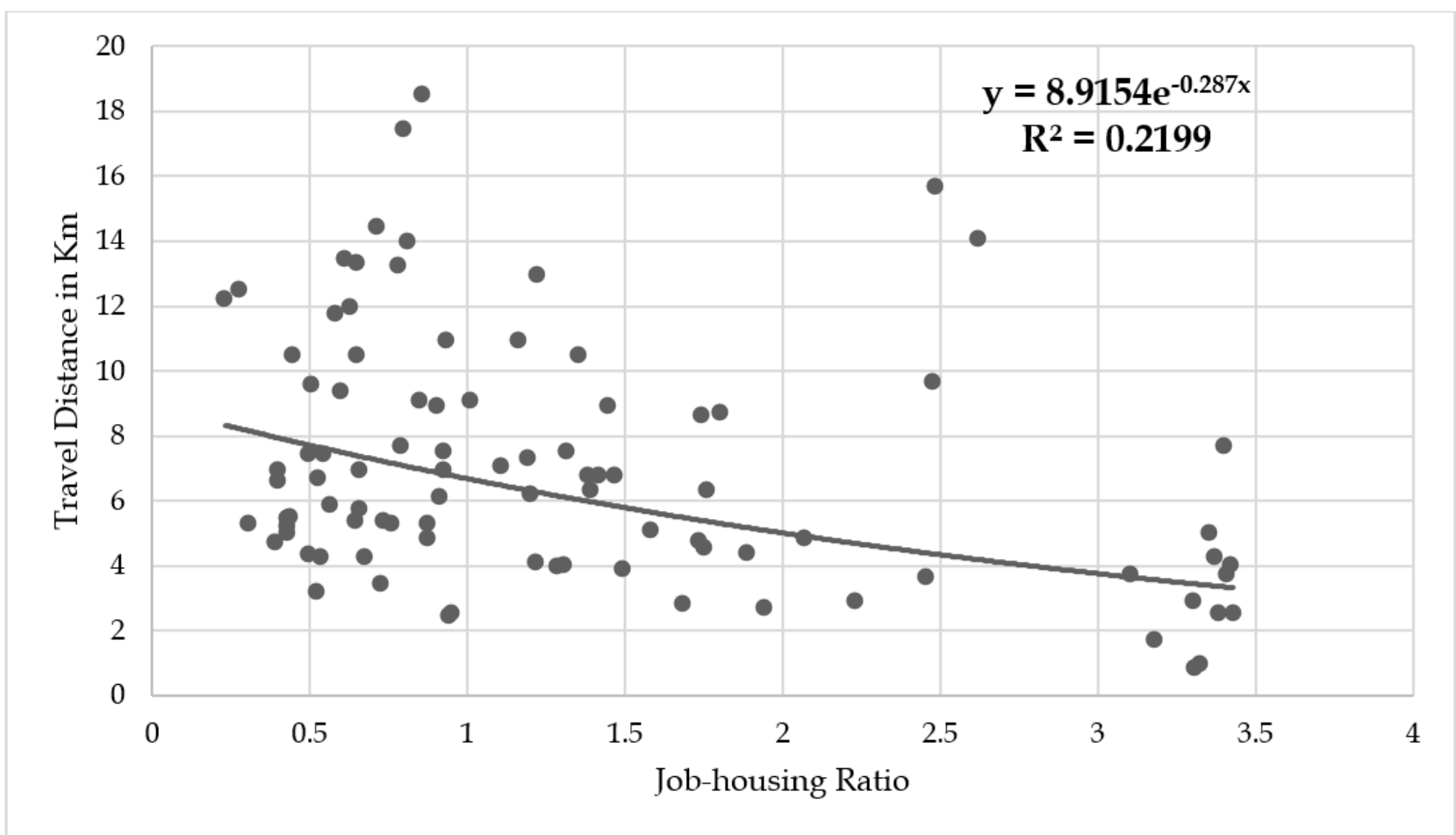

Fig. 6 Average commuting distance of TAZ and their corresponding Job-housing Ratio.

in correspondence to JHR. From the best fitted exponential curves, slopes at particular job housing ratio points are calculated and shown in Table 7.
The slopes of both curves are negative which implies that both commuting time and distance decrease with the increase in JHR. 
Table 7 Slopes of fitted exponential curves at different points of Job-Housing Ratio

\begin{tabular}{|c|c|c|}
\hline $\begin{array}{l}\text { Job-Housing } \\
\text { Ratio }\end{array}$ & $\begin{array}{l}\text { Commuting time } \\
\text { reduction } \\
\text { in minutes }\end{array}$ & $\begin{array}{l}\text { Commuting } \\
\text { distance reduction } \\
\text { in } \mathrm{km}\end{array}$ \\
\hline 0.2 & -3.82 & -2.42 \\
\hline 0.4 & -3.74 & -2.28 \\
\hline 0.6 & -3.66 & -2.16 \\
\hline 0.8 & -3.59 & -2.03 \\
\hline 1.0 & -3.52 & -1.92 \\
\hline 1.2 & -3.45 & -1.81 \\
\hline 1.4 & -3.38 & -1.71 \\
\hline 1.6 & -3.31 & -1.62 \\
\hline 1.8 & -3.24 & -1.53 \\
\hline 2.0 & -3.18 & -1.44 \\
\hline 2.2 & -3.11 & -1.36 \\
\hline 2.4 & -3.05 & -1.29 \\
\hline 2.6 & -2.99 & -1.21 \\
\hline 2.8 & -2.93 & -1.15 \\
\hline 3.0 & -2.87 & -1.08 \\
\hline 3.2 & -2.81 & -1.02 \\
\hline 3.4 & -2.75 & -0.96 \\
\hline
\end{tabular}

The slopes of both curves descend with the increase of the JHR, but with a decreasing rate. For example, the slope of the best fitted exponential curve of commuting time (distance) vs JHR is $-3.66(-2.16)$ when the JHR is at 0.6 , but it falls to $-3.18(-1.44)$ due to the increase of the ratio to 2 . A oneunit change in JHR at point 0.6 results in about 220 seconds $(2.16 \mathrm{~km})$ reduction in commuting time (distance) while at point 2 , a one-unit change in JHR affects about 190 seconds $(1.44 \mathrm{~km})$ reduction in commuting time (distance). This finding suggests that the marginal benefit of reducing commuting time or distance is maximal when JHR moves towards Housing-rich neighborhood to Balanced neighborhood while the marginal benefit is minimal when JHR moves towards Balanced neighborhood to Employment-rich neighborhood. In other words, in Housing-rich neighborhood, JHR has a strong influence to reduce commuting time or distance, while this effect is somewhat weak in Employment-rich neighborhoods.

\section{Discussion}

This study authenticates that people living in Housing-rich neighborhoods have to make longer trips. The study shows that an increase in JHR in Housing-rich neighborhood would exert substantial influence to reduce commuting time or distance, while this influence would be somewhat weak in Employment-rich neighborhoods, and this finding is in line with the study conducted by Peng 1997. In employment-rich neighborhoods, the number of jobs typically outnumbers the number of housings. Therefore, the effect of increased JHR in Employment-rich neighborhood is that new trips further away from the neighborhood would be attracted to the area, which suggests that increased JHR in Employment-rich neighborhood has little effect on its home-based trip generation. Rather, it indirectly lengthens commuting distance and time of trips of Housing-rich neighborhoods. Furthermore, Employment-rich neighborhoods have to experience huge congestion which diminishes the effect of shortening commuting time.

The results of the study are in line with the colocation hypothesis which suggests Job-housing balance has an efficacious influence to shorten commuting distance and time (Cervero 1989). Colocation hypothesis recommends that a concurrent rearrangement between housing and working in a free market system results in Job-housing balance. Particularly, in a perfect job and housing market, workers and jobs follow each other freely which paves the way for the achievement of Job-housing balance (Gordon et al. 1991). Consequently, in an imperfect market, there is an unlikely chance of mutual rearrangement of jobs and housing resulting in longer commuting distance and time (Peng, 1997). Furthermore, according to the co-location hypothesis, traditional planning discouraged Jobhousing balance which results in lengthening commuting time and distance (Cervero, 1989). While Zhao et al. (2011) authenticated that government interventions in jobs-housing balance exert substantial impact to shorten commuting time in Beijing. Therefore, the neighborhoods of Dhaka possessing Housing-rich character should receive institutionalized housing and job adjustment. Therefore, it can be recommended explicitly that government intervention is important for the development and distribution of affordable housing to foster a balance between local jobs and housing. And the benefits of Job-housing Balance can not be received by only the initiatives in numeral match between jobs and housing but the initiatives in obtaining the actual correspondence between housing, jobs, and workers' socioeconomic characteristic (Wu et al. 2015; Sultana 2002). Furthermore, to balance jobs and housings in an area, various initiatives such as, tax sharing, financial incentives for living near to the job location, etc. should be taken in action (Cervero 2006). Employment-rich neighborhoods should not be redirected to a balanced one through decreasing the employment op- 
portunities rather transferring unemployed individuals from low income households in those areas. Another important issue of using the JHR as a policy tool is defining an appropriate ratio for a different geographical unit. This ratio should be fixed based on the scale of the study, local needs, as well as the economic structure of the area. For instance, the Sacramento Area Council of Government (SACOG 2012) or Metropolitan Washington area (Fairfax County Department Planning and Zoning 2012), using Job-housing at the regional level based on the current level of Job-housing balance in neighboring regions. In the case of Dhaka city, a massive number of commuters living in suburbs i.e. Tongi, Gazipur, Savar, Narayanganj, etc. have to travel into the core part of the city for work purpose which produces a large number of interzonal trips (Rahman 2017). In contrast, the southern part of the city having a more balanced JHR is performing better as residents are working locally. An average trip generation or travel distance is lower in these parts of the city as communities tend to generate more intra-zonal trips. A balance JHR in peri-urban or suburban areas can reduce a considerable number of inter-zonal trips made every day. For which, adequate employment generation with balanced neighborhood amenities would be required.

In response to guide the land use pattern of the city, the DSP plan has several policy recommendations for upcoming years. For example, the plan outlines facilitating the development of the ICT sector in the Dhaka Core area (DSP 2016-2025: 149). A feasibility study can be carried out to establish these IT industries in "housing-rich" areas where there is a lack of locally available jobs for middle to highincome groups. Besides, DSP has plans to provide housing options close to job locations for major industrial clusters (DSP 2016-2025: 8). To accommodate employment options for low-income groups, the plan outlines facilitating the provision of infrastructural facilities and services within reasonable commuting distance. Planners have a role in guiding the market force or understanding the free market forces. A complete understanding of how market forces affect job-housing proximity, future growth of cities, and urban travel pattern of the residents is required to maintain an appropriate jobhousing balance.

\section{Conclusions}

The primary aim of the paper was to quantify the existing jobs-housing scenario along with accessing the degree of balance in terms of the spatial distribution of jobs and housing of the neighborhoods (TAZs) of two city corporation areas. The study has explored the relation of Job-housing balance with travel behavior, specifically commuting time for work trips of the residents. Study output reveals that the JHR value is varied across the geographic unit. Applying to recommend a range of jobshousing ratio, all $(\mathrm{N}=92)$ the neighborhoods have been categorized into three classes. Where, 39.13\% of the neighborhoods are identified as housing-rich; $39.13 \%$ are identified as Perfect balanced, and the rest $21.73 \%$ are identified as job-rich. The average commuting time and distance significantly vary between these identified neighborhoods: people living in housing-rich neighborhoods generate longer trips than other neighborhood types. The study reveals that there is an exponential relationship between JHR and commuting time and JHR and travel distance. The marginal benefit of reducing commuting time or distance is maximal when job housing ratio moves away from Housing-rich neighborhood to Balanced neighborhood while the marginal benefit is minimal when JHR moves away from Balanced neighborhood to Employment-rich neighborhood. These findings signify crucial policy implications: land-use policies for the achievement of a balance between jobs and housings which are mainly focused on the Housing-rich neighborhoods affect a significant portion of the city and thus have a substantial impact on the overall commuting patterns. Future research should study the impact of Jobhousing balance on the commuter travel pattern of greater Dhaka Regions. Moreover, future studies should explore the demand and supply of both housing and employment opportunities in accordance with local needs for studying Job-housing balance.

\section{References}

Aslam SAB, Masoumi HE, Hussain SA (2019) Urban travel characteristics in relation with jobs-housing balance and accessibility: results of a survey in Lahore, Pakistan. GeoScape 13(1): $31-54$.

Bento AM, Cropper ML, Mobarak AM ,Vinha K (2005) The effects of urban spatial structure on travel demand in the United States. Review of Economics and Statistics 87(3): 466-478.

Bangladesh Bureau of Statistics (2011) Population and Housing Census, 2011: Urban Area Report. Planning Division, Ministry of Planning, Dhaka, Bangladesh. 


\section{sciendo}

Bangladesh Bureau of Statistics. (2015) Economic Census 2013. Available at: <http://203.112.218.65:8008/WebTestApplication/userfiles/Image/EcoCen13/FinalReport\%20Part\%201.pdf>

Cervero R (1989) Jobs-housing balancing and regional mobility. Journal of the American Planning Association 55(2): 136-150.

Cervero R (1991) Jobs housing balance as a public policy. Urban Land 50(10): 10-14.

Cervero R (1996) Jobs-housing balance revisited: Trends and impacts in the San Francisco Bay Area. Journal of the American Planning Association 62(4): 492-511.

Cervero R, Duncan M (2006) Which reduces vehicle trave more: Jobs-housing balance or retail-housing mixing?. Journal of the American Planning Association 72(4): 475-490.

Downs A (1992) Stuck in traffic: Coping with peak-hour traffic congestion. Brookings Institution Press.

Downs A (2005) Still stuck in traffic: Coping with peak-hour traffic congestion. Brookings Institution Press.

Dhaka population 2020 (Demographics, maps, graphs) (2020) Available at: <https://worldpopulationreview.com/worldcities/dhaka-population>

Draft Dhaka structure plan report 2016-2035 (Full volume) (n.d.). Available at: <https://www.academia.edu/31508051/. Draft_Dhaka Structure_Plan_Report_2016-2035_Full_Volume>

Dhaka Transport Coordination Authority (DTCA) (2015) The Project on the Revision and Updating of the Strategic Transport Plan for Dhaka. Available at: < https://dtca.portal.gov.bd/sites default/files/files/dtca.portal.gov.bd/page/2c9ed

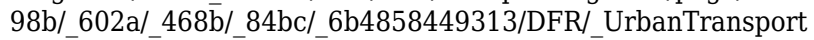
$\% 20$ Policy\%20(Edited).pdf>

Ewing R (2019) Best development practices: Doing the right thing and making money at the same time. Routledge, London.

Ewing R, Cervero R (2001) Travel and the built environment: A synthesis. Transportation Research Record: Journal of the Transportation Research Board 1780 (1): 87-114.

Frank LD (1994) Relationships between land use and travel behavior in the Puget Sound region. Washington State Transportation Center, Seattle.

Frank LD (1996) An analysis of relationships between urban form (density, mix, and jobs: Housing balance) and travel behavior (mode choice, trip generation, trip length, and commuting time). Transportation Research Part A: Policy and Practice 30(1): 76-77.

Giuliano G (1991) Is jobs-housing balance a transportation issue?. San Francisco: The University of California Transportation Center Transportation research record 1305: 305-312.

Horner M W (2008) Optimal accessibility landscapes? Development of a new methodology for simulating and assessing jobs-Housing relationships in urban regions. Urban Studies 45(8): 1583-1602.

Horner MW, Mefford JN (2007) Investigating urban spatial mismatch using job-housing indicators to model home-work separation. Environment and Planning A 39: 1420-1440.

Levine J (1998) Rethinking accessibility and jobs-housing balance. Journal of the American Planning Association 64(2): 133-149.

Loo B P, Chow A S (2011) Jobs-housing balance in an era of population decentralization: An analytical framework and a case study. Journal of Transport Geography 19(4): 552-562.

Margolis J (1957) Municipal fiscal structure in a metropolitan region. Journal of Political Economy, 65(3): 225-236.
Miller E J, Ibrahim Ac(1998) Urban form and vehicular travel: Some empirical findings. Transportation Research Record: Journal of the Transportation Research Board, 1617(1): 18-27.

Miller J S (2010) Feasibility of using jobs/housing balance in Virginia statewide planning. Virginia Transportation Research Council, Charlottesville.

Niedzielski MA, O'Kelly ME, Boschmann EE (2015) Synthesizing spatial interaction data for social science research: Validation and an investigation of spatial mismatch in Wichita, Kansas. Computers, Environment and Urban Systems 54: 204-218

Optimized hot spot analysis-ArcGIS pro | Documentation. (2019, December 10). Available at: <https://pro.arcgis.com/en/pro-app/tool-reference/spatial-statistics/optimizedhot-spot-analysis.htm>

Peng Z (1997) The jobs-housing balance and urban commuting. Urban Studies 34(8): 1215-1235.

SACOG (Sacramento Area Council of Government). (2012, February). Metropolitan transportation plan sustainable communities strategy (MTP/SCS 2035). Available at: <http://www.sacog.org/2035/draft-final-mtpscs>

SCAG (2001) the new economy and job-housing balance in Southern California.

Southern California Association of Governments, Los Angeles, pp. $19-20$

Rahman MH, Islam M, Neema MN (2019) Compactness of Neighborhood Spatial Structure: A Case Study of Selected Neighborhoods of DNCC and DSCC Area. Paper presented at International Conference on Sustainability in Natural and Built Environment (iCSNBE 2019), Dhaka, Bangladesh. Available at: <http://www.icsnbe.net.au/proceedings/2019/iCSNBE2019 Proceedings.pdf>

Rahman M (2017) Study on the mode choice behavior of the commuters living in the suburban areas of Dhaka (Master's thesis, Bangladesh University of Engineering and Technology, Dhaka, Bangladesh). Available at: <http://lib.buet.ac.bd:8080/xmlui/handle/123456789/4570>

Sultana S (2002) Job/Housing imbalance and commuting time in the Atlanta metropolitan area: Exploration of causes of longer commuting time. Urban Geography 23(8): 728-749.

Ta N, Chai Y, Zhang Y, Sun D (2016) Understanding job-housing relationship and commuting pattern in Chinese cities: Past, present and future. Transportation Research Part D: Transport and Environment 52: 562-573

Wang D, Chai Y (2009) The jobs-housing relationship and commuting in Beijing, China: The legacy of Danwei. Journal of Transport Geography 17(1): 30-38.

Wu Q, Zhang M, Yang D (2015) Jobs-housing balance: The right ratio for the right place. Recent Developments in Chinese Urban Planning: $311-333$.

Yang J, Ferreira J (2005) Evaluating measures of job-housing proximity: Boston and Atlanta, 1980-20001. Access to Destinations: $171-192$

Zhao P, Lu B, Linden GJ (2009) The effects of transport accessibility and jobs-housing balance on commuting time: Evidence from Beijing. International Planning Studies 14(1): 65-83.

Zhao P, Lü B, Roo GD (2011) Impact of the jobs-housing balance on urban commuting in Beijing in the transformation era. Journal of Transport Geography 19(1): 59-69. 